\title{
THỰC TRANG KIÊTT SỨC NGHỀ NGHIÊPP CỦA BÁC SĨ VÀ ĐIỀU DƯỡNG TẠI MộT BỆNH VIỆN HẠNG 1 Ở VIỆT NAM, 2020
}

\section{TÓM TẮT}

Kiệt sức ở nhân viên y tế là một vấn đề sức khoẻ nghề nghiệp có thể dẫn đến sai sót y khoa, có liên quan đến tî̉ lệ tử vong cao hơn và làm giảm hài lòng người bệnh. Nghiên cứu được tiến hành với mục tiêu mô tả thực trạng kiệt sức nghề nghiệp ở bác sĩ và điều dướng tại một bệnh viện chuyên khoa hạng 1 ở Viêt Nam. Nghiên cứu cắt ngang được thực hiện từ tháng 02/2020 đến tháng 09/2020 tại các Khoa lâm sàng của bệnh viện bằng bảng hỏi định lượng trên 226 bác sĩ và điều dưỡng. Nghiên cứu sử dụng thang đo kiệt sức Maslach (MBI) phiên bản đã được chuẩn hóa tại Việt Nam. Kết quả nghiên cứu cho thấy tỉ lệ can kiêt cảm xúc mức cao chiếm $72,12 \%$; tỉ lệ tính tiều cực mức cao chiếm $78,77 \%$; tî lệ hiệu quả cá nhân mức cao chiếm $67,26 \%$. Khi đánh giá kiệt sức chung, kết quả cho thây tỉ lệ có kiệt sức chung là $75,22 \%$. Nghiên cứu khuyến cáo cần áp dụng các biện pháp để phòng ngừa kiệt sức nghề nghiệp ở bác sĩ và điều dưỡng.

Tư khoá: kiệt sức, nghề nghiệp, bác sĩ, điêu dưỡng, bệnh viện

\section{SUMMARY \\ SITUATION OF BURNOUT AMONG HEALTH WORKERS AT A CENTRAL HOSPITAL IN VIETNAM, 2020}

Burnout is one of the occupational health problems that might lead to medical advert events in hospitals. This might lead to mortality and reduce patient satisfaction. The study aimed to investigate the situation of occupational burnout among doctors and nurses at a central hospital in Vietnam. Cross sectional study was conducted from February to September 2020 using standardized Maslach burnout inventory (MBI) questionnaire. Results show that $75.22 \%$ of doctors and nurses experienced to occupational burnout. Prevalence of doctors and nurses experienced to emotional exhaustion, depersonalization and personal accomplishment problems was $72.12 \%, 78.77 \%$ and $67.26 \%$. It is recommended that the hospital board should apply intervention measures to prevent burnout among health workers at the hospital.

Keywords: burnout, occupational, doctor, nurse, hospital

\section{I. ĐĂT VẤN ĐỀ}

Kiệt sức nghề nghiệp là hiện tượng cạn kiệt cảm xúc trong công việc, dẫn đến tư duy công

*Trường Đại học Y tế công cộng

Chịu trách nhiệm chính: Nguyễn Ngọc Bích

Email: nnb@huph.edu.vn

Ngày nhân bài: 2.3.2021

Ngày phản biên khoa học: 26.4.2021

Ngày duyệt bài: 7.5.2021

\section{Nguyễn Ngọc Bích*, Vũ Thái Sơn*}

việc không hiệu quả bắt nguồn từ những căng thẳng trong thời gian dài (1).

Một nghiên cứu phân tích tổng hợp trên 182 công trình nghiên cứu khắp thế giới cho thấy tỉ lệ kiệt sức khỏe nhân viên y tế (NVYT) ước lượng khoảng $67 \%$ (dao động từ 0 đến 80,5\%) (2). Tại Việt Nam, theo một nghiên cứu công bố năm 2018 cho thấy gần 20\% điều dưỡng lâm sàng tại Việt Nam đang làm việc trong tình trạng kiệt sức (3).

Hậu quả của kiệt sức không chỉ giới hạn ảnh hưởing trên sức khỏe cá nhân của nhân viên y tế; nhiều nghiên cứu đã chứng minh rằng sự kiệt sức còn ảnh hưởng đến hiệu quả chăm sóc người bệnh như dẫn đến sai sót y khoa (4), làm tăng tỉ lệ khiếu nại ở người bệnh (5), tî lệ tử vong cao hơn ở người bệnh (6).

Ớ cấp độ tổ chức, kiệt sức dẫn đến tỉ lệ nghỉ việc cao hoặc làm gia tăng suy nghĩ bỏ việc ở nhân viên y tế bao gồm cả bác sĩ và điều dưỡng. Nó cũng dẫn đến giảm hiệu quả năng suất lao động. Do đó, kiệt sức có thể góp phần vào tình trạng thiếu bác sĩ và điêu dưỡng trong tương lai (7).

Nghiên cứu đã được tiến hành với mục tiêu mô tả thực trạng kiệt sức của bác sĩ và điều dưỡng tại một Bệnh viện hạng 1 ở Việt Nam

\section{II. ĐỐI TƯỢNG VÀ PHƯƠNG PHÁP NGHIÊN CỨU}

2.1. Thiết kế và cỡ mẫu nghiên cứu: Nghiên cứu cắt ngang sử dụng bộ câu hỏi định lượng về kiến thức trên 226 bác sĩ và điều dưỡng tại các khoa lâm sàng của bệnh viện. Nghiên cứu được tiến hành từ tháng 02/2020 đến tháng 09/2020.

2.2. Công cự thu thập số liệu. Phần khảo sát hội chứng kiệt sức nghề nghiệp theo thang đo Maslach (MBI). Thang đo MBI đã được chứng minh độ tin cậy và tính giá trị thông qua các nghiên cứu. Wickramasinghe và cs (2018) khi thực hiện nghiên cứu đã kết luận hệ số tin cậy Cronbach alpha của 3 khía cạnh lần lượt là 0,$837 ; 0,869$ và 0,881 , kiểm định độ tin cậy giữa hai lần đánh giá cũng cho thấy độ tương quan cao với $p<0,001$ (63). Bảng hỏi được sử dụng là bảng MBI gồm 22 câu hỏi chia thành 3 khía cạnh bao gồm: (1) Cạn kiệt cảm xúc (gồm 9 câu hỏi), (2) Tính tiêu cực (gồm 5 câu hỏi) và (3) Hiệu quả cá nhân (gồm 8 câu hỏi) theo phiên bản đã được chuẩn hóa tại Việt Nam sau khi 
nghiên cứu trên điều dưỡng lâm sàng (5). Phiên bản 22 câu hỏi cũng được đánh giá là phiên bản có nhiều ưu điểm về mặt văn hóa và tin cậy trong đo lường (64). Mức độ kiệt sức của từng câu hỏi được đánh giá theo thang Likert 7 mức độ với:

- 0 là Không bao giờ

- 1 là Mỗi năm ít nhất vài lần

- 2 là Mỗi tháng ít nhất một lần

- 3 là Mỗi tháng vài lần

- 4 là Mỗi tuần một lần

- 5 là Mối tuần vài lần

- 6 là Mỗi ngày

Các thông tin thu được hoàn toàn trung thực và tin cậy. Được sử dụng nhằm phục vụ mục đích nghiên cứu không phục vụ vào mục đích gì khác, không làm ảnh hưởng đển nhân viên y tế và uy tín của bệnh viện.

Đề cương nghiên cứu được Hội đồng Đạo đức Trường đại học $Y$ tế Công cộng thông qua theo quyết định số 410/2020/YTCC -HD3 trước khi tiến hành triển khai.

\section{KẾT QUẢ NGHIÊN CứU}

Bảng 3.1. Thông tin chung về đôî tượng nghiên cứu

\begin{tabular}{|c|c|c|c|}
\hline Biến số & Nội dung & $\begin{array}{c}\text { Tân } \\
\text { số }\end{array}$ & $\begin{array}{c}\text { Tỉ lệ } \\
\mathbf{\%}\end{array}$ \\
\hline \multirow{2}{*}{ Giới tính } & Nam & 38 & 16,81 \\
\cline { 2 - 4 } & Nữ & 188 & 83,19 \\
\hline \multirow{2}{*}{$\begin{array}{c}\text { Tôn } \\
\text { giáo }\end{array}$} & Phật giáo & 72 & 31,86 \\
\cline { 2 - 4 } & Thiên Chúa giáo & 27 & 11,95 \\
\cline { 2 - 4 } & Không tôn giáo & 127 & 56,19 \\
\hline \multirow{2}{*}{ Dân tộc } & Kinh & 214 & 94,69 \\
\cline { 2 - 4 } & Hoa & 12 & 5,31 \\
\hline \multirow{3}{*}{$\begin{array}{c}\text { Trình độ } \\
\text { học vấn }\end{array}$} & Sau đại học & 61 & 26,99 \\
\cline { 2 - 4 } & Đại học & 78 & 34,51 \\
\cline { 2 - 4 } & Cao đằng & 51 & 22,57 \\
\cline { 2 - 4 } & Trung cấp & 36 & 15,93 \\
\hline
\end{tabular}

Bảng 3.1 cho thấy phân lớn người tham gia nghiên cứu là nữ nhân viên y tế với tỷ lệ cao gấp 5 lần so với nam giới, tỉ lệ nữ, nam lần lượt là $83,19 \%$ và $16,81 \%$. Hơn một nửa người tham gia không có tôn giáo $(56,19 \%)$, tỉ lệ Phật giáo và Thiên Chúa giáo lần lượt là $31,86 \%$ và $11,95 \%$. Đa số, nhân viên y tế tham gia nghiên cứu là dân tộc Kinh $(94,69 \%)$, còn lại là dân tốc
Hoa với 12 người (chiếm tỉ lệ 5,31\%).

Nhân viên y tế có trình độ học vấn là đại học chiếm ưu thế nhất $(34,51 \%)$, sau đó là trình độ thac sĩ/chuyên khoa I $(26,99 \%)$, trình đô học vấn cao đẳng, trung cấp lần lượt $22,57 \%$ và $15,93 \%$.

Bảng 3.2. Đặc điểm việc làm thêm

\begin{tabular}{|c|c|c|c|}
\hline Biến số & $\begin{array}{c}\text { Nội } \\
\text { dung }\end{array}$ & $\begin{array}{c}\text { Tấn } \\
\text { số }\end{array}$ & $\begin{array}{c}\text { Tỉ lệ } \\
\text { \%o }\end{array}$ \\
\hline Làm thêm liên & Có & 39 & 17,26 \\
\cline { 2 - 4 } quan chuyên môn & Không & 187 & 82,74 \\
\hline Làm thêm ngoài & Có & 99 & 43,81 \\
\cline { 2 - 4 } chuyên môn & Không & 127 & 56,19 \\
\hline
\end{tabular}

Khảo sát về tình trạng làm thêm sau giờ làm ở bệnh viện, kết quả thấy "làm thêm liên quan chuyên môn" tỉ lệ có là $17,26 \%$, tỉ lệ không là $82,74 \%$; "làm thểm ngoài chuyên môn" tî lệ có, không lần lượt là $43,81 \%$ và $56,19 \%$.

Bảng 3.3. Đặc điểm ca trực

\begin{tabular}{|c|c|c|c|}
\hline Biến số & Nội dung & Tân số & Tỉ lệ \% \\
\hline \multirow{4}{*}{$\begin{array}{c}\text { Đặc điểm } \\
\text { ca trực }\end{array}$} & Làm giờ hành chính & 65 & 28,76 \\
\hline & Có trực ca 12 tiếng & 23 & 10,18 \\
\hline & Có trực ca 16 tiếng & 100 & 44,25 \\
\hline & Có trực ca 24 tiếng & 38 & 16,81 \\
\hline \multirow{4}{*}{$\begin{array}{l}\text { Tần suất } \\
\text { trực đêm }\end{array}$} & Không trực đêm & 53 & 23,45 \\
\hline & Mối tuần 1 lần & 102 & 45,13 \\
\hline & Mối tuần 2 -3 lần & 61 & 26,99 \\
\hline & Trên 3 lần mối tuần & 10 & 4,42 \\
\hline Biên số & TB \pm ĐLC & $\begin{array}{c}\text { Giá trị } \\
\text { nhỏ } \\
\text { nhất }\end{array}$ & $\begin{array}{l}\text { Giá trị } \\
\text { lớn } \\
\text { nhất }\end{array}$ \\
\hline $\begin{array}{l}\text { Số giờ } \\
\text { việc t } \\
\text { hinh } / 1\end{array}$ & $47,73 \pm 11,27$ & 8 & 80 \\
\hline
\end{tabular}

Nhân viên y tế tham gia nghiên cứu có trực ca 16 tiếng chiếm ưu thế $44,25 \%$, tiếp đến là làm giờ hành chính chiếm $28,76 \%$, sau đó là trực ca 24 tiếng chiếm $16,81 \%$ và cuối cùng là trực ca 12 tiếng 10,18\%.

Đa số người tham nghiên cứu này có tần suất trực đêm mỗi tuần một lần $(45,13 \%)$; không trực đêm, mỗi tuần 2-3 lần, trên 3 lần mối tuần lần lượt là $23,45 \%, 26,99 \%$ và $4,42 \%$.

Số giờ làm việc trung bình/1tuần của người tham gia nghiên cứ có giá trị trung bình là 47,73 giờ (ĐLC: 11,27), với số giờ làm việc trung bình/1 tuần nhỏ nhất là 8 giờ và cao nhất là 80 giờ.

Bảng 3.4. Đặc điểm công việc ngoài việc chuyên môn

\begin{tabular}{|c|c|c|c|c|}
\hline Biến số & Bác sî́ & Điều dưỡng & \multicolumn{1}{c|}{ Tổng } & Tỉ lệ \\
\hline Có & Trực điện thoại, các kênh thông tin đại chúng & \\
\hline Không & $13(15,85)$ & $27(18,75)$ & 40 & 17,70 \\
\hline \multicolumn{7}{|c|}{ Hồ sơ bệnh án, báo hiếm y tế } \\
\hline
\end{tabular}




\begin{tabular}{|c|c|c|c|c|}
\hline Có & $57(69,51)$ & $96(66,67)$ & 153 & 67,70 \\
\hline Không & $25(30,49)$ & $48(33,33)$ & 73 & 32,30 \\
\hline \multicolumn{5}{|c|}{ Quản lý chuyên môn } \\
\hline Có & $24(29,27)$ & $14(9,72)$ & 38 & 16,81 \\
\hline Không & $58(70,73)$ & $130(90,28)$ & 188 & 83,19 \\
\hline \multicolumn{5}{|c|}{ Quản lý hành chính } \\
\hline Có & $9(10,98)$ & $17(11,81)$ & 26 & 11,50 \\
\hline Không & $73(89,02)$ & $127(88,19)$ & 200 & 88,50 \\
\hline \multicolumn{5}{|c|}{ Mạng lưới Quản lý chất lượng } \\
\hline Có & $8(9,76)$ & $15(10,42)$ & 23 & 10,18 \\
\hline Không & $74(90,24)$ & $129(89,58)$ & 203 & 89,82 \\
\hline
\end{tabular}

Ngoài vấn đề làm việc liên quan đến chuyên môn, $17,70 \%$ nhân viên y tế tham gia nghiên cứu có trực điện thoại, các kênh thông tin truyền thông đại chúng; $67,70 \%$ có làm hồ sơ bệnh án, bảo hiểm y tế; $16,81 \%$ có quản lý chuyên môn; $11,50 \%$ có quản lý hành chính và $10,18 \%$ có làm các công việc mạng lưới quản lý chất lượng.

Bảng 3.5. Trung bình điểm các khía cạnh của hội chứng kiệt sức

\begin{tabular}{|c|c|c|c|}
\hline Biến số & TB \pm ĐLC & $\begin{array}{c}\text { Giá trị } \\
\text { nhó } \\
\text { nhất }\end{array}$ & $\begin{array}{c}\text { Giá trị } \\
\text { lớn } \\
\text { nhất }\end{array}$ \\
\hline $\begin{array}{c}\text { Điếm cạn kiệt cảm } \\
\text { xúc (EE) }\end{array}$ & $\begin{array}{c}31,20 \\
\pm 9,76\end{array}$ & 3 & 52 \\
\hline $\begin{array}{c}\text { Điếm tính tiêu cực } \\
\text { (DP) }\end{array}$ & $\begin{array}{c}13,17 \\
\pm 4,51\end{array}$ & 2 & 23 \\
\hline $\begin{array}{c}\text { Điếm hiệu quả cá } \\
\text { nhân (PA) }\end{array}$ & $\begin{array}{c}30,60 \\
\pm 6,92\end{array}$ & 18 & 46 \\
\hline
\end{tabular}

Đánh giá các khía cạnh của hội chứng kiệt sức, nghiên cứu chúng tôi ghi nhận: điểm cạn kiêt cảm xúc trung bình là 31,20 (ĐLC: 9,76) với điểm nhỏ nhất là 3 và điểm lớn nhất là 52 . Điểm tính tiêu cực trung bình là 13,17 (ĐLC: 4,51), điểm tính tiêu cực nhỏ nhất là 13,17 và điểm tính tiêu cực lớn nhất là 23. Và điểm hiệu quả cá nhân trung bình là 30,60 (ĐLC: 6,92), với giá trị nhỏ nhất là 18 và giá trị cao nhất là 46 .

Bảng 3.6. Tỉ lệ kiệt sức nghề nghiệp theo các khía cạnh

\begin{tabular}{|c|c|c|c|}
\hline Biến số & Nội dung & Tân số & $\begin{array}{c}\text { Tỉ lệ } \\
\% \%\end{array}$ \\
\hline \multirow{3}{*}{$\begin{array}{l}\text { Cạn kiết } \\
\text { cảm xúc }\end{array}$} & Không & 26 & 11,50 \\
\hline & Trung bình & 37 & 16,38 \\
\hline & Cao & 163 & 72,12 \\
\hline \multirow{3}{*}{$\begin{array}{l}\text { Tính } \\
\text { tiêu cực }\end{array}$} & Không & 18 & 7,96 \\
\hline & Trung bình & 30 & 13,27 \\
\hline & Cao & 178 & 78,77 \\
\hline \multirow{3}{*}{$\begin{array}{l}\text { Hiệu } \\
\text { quả cá } \\
\text { nhân }\end{array}$} & Không & 28 & 12,39 \\
\hline & Trung bình & 46 & 20,35 \\
\hline & Cao & 152 & 67,26 \\
\hline \multirow{2}{*}{$\begin{array}{l}\text { Kiệt sức } \\
\text { chung }\end{array}$} & Không & 56 & 24,78 \\
\hline & Có & 170 & 75,22 \\
\hline
\end{tabular}

Khi xét mức độ các khía cạnh của hội chứng kiệt sức, nghiên cứu ghi nhận các khía cạnh cạn kiệt cảm xúc, tính tiêu cực, hiệu quả cá nhẩn mức độ cao điều chiếm ưu thế. Cụ thể, tỉ lệ cạn kiệt cảm xúc mức cao chiếm ưu thế $72,12 \%$; tì lệ tính tiêu cực mức cao chiếm $78,77 \%$; tỉ lệ hiệu quả cá nhân mức cao chiếm $67,26 \%$.

Khi đánh giá kiệt sức chung, kết quả cho thây tỉ lệ có kiệt sức chung là $75,22 \%$ và tỉ lệ không là $24,78 \%$.

\section{BÀN LUÂN}

Trong nghiên cứu phân tích tổng hợp của Rotenstein (2018) đã nhận thấy 11 trên tổng số 182 nghiên cứu được tham khảo (chiếm tỉ lệ $67 \%$ ) báo cáo rằng tình trang kiệt sức ở nhân viên y tế tổng thể dao động từ $0 \%$ đến 80,5\% (2).

Nghiên cứu này nhận thây tỉ lê kiệt sức chung ở nhân viên y tế của bệnh viện là $75,2 \%$, trong đó không có sự khác biệt về tỉ lệ giữa điều dưỡng và bác sĩ (tỉ lệ kiệt sức nghề nghiệp ở hai nhóm đối tượng này lần lượt là $75,6 \%$ và $75 \%$. So sánh với những nghiên cứu khác thì tỉ lệ kiệt sức trong nghiên cứu này nằm ở mức cao.

So với các nghiên cứu khác tại Châu Á, tỉ lệ kiệt sức nghề nghiệp ở nghiên cứu này cũng cao hởn những kết quả khác tại Nhật Bản, Trung Quốc và Iran (8) (9).

So sánh với các nghiên cứu tại Việt Nam, tỉ lệ kiệt sức này cũng có tỉ lệ cao hơn.

Nghiên cứu điều tra 811 bác sĩ, y tá, hộ lý thuộc 8 bệnh viện/viện tuyến trung ương của Nguyễn Thu Hà và Doã̃n Ngọc Hà năm 2016 cho thấy $48,6 \%$ nhân viên y tể có biểu hiện căng thẳng và kiệt sức nghề nghieễp.

Nghiên cứu của Nguyễn Thị Thu Hương (2018) cho thấy tỉ lệ kiệt sức trên 500 điều dưỡng lâm sàng đang làm việc ở các khoa tại ba bệnh viện công thuộc tỉnh Hải Phòng, Việt Nam là $0,7 \%$ ở mức độ nặng và $15,8 \%$ ở mức độ trung bình và $17,2 \%$ điều dưỡng cảm thây mệt mỏi (3). 


\section{KẾT LUẬN}

Tỉ lệ cạn kiêt cảm xúc mức cao chiếm $72,12 \%$; tỉ lệ tính tiêu cực mức cao chiếm $78,77 \%$; tỉ lệ hiệu quả cá nhân mức cao chiếm $67,26 \%$. Khi đánh giá kiệt sức chung, kết quả cho thây tỉ lệ có kiệt sức chung là 75,22\%.

Kết quả nghiên cứu cho thấy cân có một số biện pháp can thiệp như phân bố lịch trực đêm, tăng ca và trực cuối tuân hợp lý để tránh tình trạng một bác sĩ hay điều dưỡng phải trực ngoài giờ quá nhiêu, nâng cao sức khỏe thể chất và tinh thân của nhân viên y tế để đáp ứng với nhu câu của ngành, nghê.

\section{TÀI LIÊU THAM KHẢO}

1. Reith, P. T. Burnout in United States Healthcare Professionals: A Narrative Review. Cureus. 2018;10(12):e3681-e.

2. Rotenstein, S. L, Torre, M., Ramos, A. M, et al. Prevalence of Burnout Among Physicians: A Systematic Review. Jama. 2018;320(11):1131-50.

3. Nguyen, T. HT, Kitaoka, K., Sukigara, M., et al. Burnout Study of Clinical Nurses in Vietnam:
Development of Job Burnout Model Based on Leiter and Maslach's Theory. Asian Nursing Research. 2018;12(1):42-9.

4. Shanafelt, D. T, Balch, M. C, Bechamps, G., et al. Burnout and medical errors among American surgeons. Annals of surgery. 2010;251(6):995-1000.

5. Balch, M. C, Oreskovich, R. M, Dyrbye, N. L, et al. Personal consequences of malpractice lawsuits on American surgeons. Journal of the American College of Surgeons. 2011;213(5):657-67.

6. Welp, A., Meier, L. L, Manser, T. Emotional exhaustion and workload predict clinician-rated and objective patient safety. Frontiers in psychology. 2014;5:1573.

7. Shanafelt, D. T, Dyrbye, N. L, West, P. C, et al. Potential Impact of Burnout on the US Physician Workforce. Mayo Clinic proceedings. 2016;91(11):1667-8.

8. Li, H., Zuo, M., Gelb, W. A, et al. Chinese Anesthesiologists Have High Burnout and Low Job Satisfaction: A Cross-Sectional Survey. Anesthesia and analgesia. 2018;126(3):1004-12.

9. Asai, M., Morita, T., Akechi, T., et al. Burnout and psychiatric morbidity among physicians engaged in end-of-life care for cancer patients: a cross-sectional nationwide survey in Japan. Psycho-oncology. 2007;16(5):421-8.

\section{ĐÁNH GIÁ ẢNH HƯởNG TRÊN TUẦN HOÀN, HÔ HẤP VÀ TÁC DỤNG KHÔNG MONG MUỐN CỦA PHƯƠNG PHÁP GIẢM ĐAU ĐƯờNG NGOÀI MÀNG CỨNG NGỰC DO BỆNH NHÂN TỰ ĐIỀU KHIỂN BẰNG ROPIVACAIN KẾT HợP VỚI FENTANYL SẢU MỔ MỞ VÙNG BỤNG}

\section{TÓM TẮT}

Mục tiêu: Đánh giá ảnh hưởng trên tuân hoàn, hô hấp và tác dụng không mong muốn của phương pháp giảm đau ngoài màng cứng ngực do bệnh nhân tự điều khiển bằng ropivacain kết hợp với fentanyl sau mổ mở vùng bụng. Phương pháp nghiên cứu: Thử nghiệm lậm sàng ngẫu nhiên có so sánh trên 03 nhóm, mỗi nhóm bao gồm 35 bệnh nhân được chỉ định phẫu thuật ổ bụng mở. Hỗn hợp thuốc sử dụng giảm đau sau mổ là fentanyl $2 \mathrm{mcg} / \mathrm{ml}$ kết hợp lần lượt với ropivacaine $0,1 \%$ ở nhóm I, ropivacaine $0,125 \%$ ở nhóm II và ropivacaine $0,2 \%$ ở nhóm III. Đánh giá ảnh hưởng trên tuần hoàn, hô hấp và các tác dụng không mong muốn xuất hiện ở người bệnh trong quá trình làm giảm đau. Kết quả: Tân số tim của người bệnh giảm rõ rệt trong 15 phút đầu sau mổ ở cả 3

*Học viện Quân y

**Bệnh viện Trung ương Quân đội 108

Chịu trách nhiệm chính: Trần Hoài Nam

Email: namb5v103@gmail.com

Ngày nhận bài: 2.3.2021

Ngày phản biện khoa học: 22.4.2021

Ngày duyệt bài: 4.5.2021
Trần Hoài Nam*, Trần Đắc Tiệp*, Nguyễn Minh Lý**, Hoàng Văn Chương*

nhóm, và duy trì ổn định từ thời điểm 30 ph trở đi. Trung bình tần số thở của các bênh nhân trong nghiên cứu giảm từ 18,3 \pm 14 xuống 16,3 \pm 0,9 (lần/phút). Không có người bệnh nào gặp tình trạng $\mathrm{SpO} 2$ dưới 95\%. Thời gian trung tiện trung bình của người bệnh dưới 40 giờ và thời gian ngồi dậy trung bình dưới 20 giờ ở cả 3 nhóm. Các tác dụng không mong muốn gặp phải là nôn, buồn nôn và đau đầu với tỷ lệ thấp $<5 \%$. Không có trường hợp nào bị tụt catheter, tụt huyết áp, ngứa hoặc run. Kết luận: Các chỉ số tuần hoàn, hô hẩp của người bệnh ổn định trong giới hạn bình thường, các tác dụng không mong muốn gặp với tỷ lệ thấp ở cả 3 nhóm.

Tư khóa: ropivacain,fentanyl, giảm đau ngoài màng cứng ngực, phẫu thuâtt ổ bụng mở.

Công trình được thực hiện tại khoa Gây mê- Bệnh viện Quân y 103 - Học viện Quẩn y từ tháng 04/2015 đển tháng 07/2017.

\section{SUMMARY \\ EVALUATION OF CIRCULATORY, RESPIRATORY \\ EFFECTS AND OTHER ADVERSE EFFECTS OF \\ PATIENT-CONTROLLED THORACIC EPIDURAL ANALGESIA USING COMBINATION OF}

